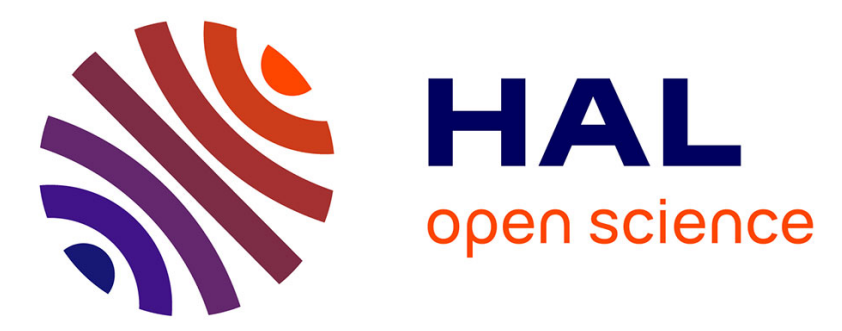

\title{
Optimization and lifecycle engineering for design and manufacture of recycled aluminium parts
}

Julien Le Duigou, Sverre Gulbrandsen-Dahl, Flore Vallet, Rikard Söderberg, Benoit Eynard, Nicolas Perry

\section{To cite this version:}

Julien Le Duigou, Sverre Gulbrandsen-Dahl, Flore Vallet, Rikard Söderberg, Benoit Eynard, et al.. Optimization and lifecycle engineering for design and manufacture of recycled aluminium parts. CIRP Annals - Manufacturing Technology, 2016, 65 (2 years), pp.149-152. 10.1016/j.cirp.2016.04.111 . hal01500121

\section{HAL Id: hal-01500121 \\ https://hal.science/hal-01500121}

Submitted on 6 Apr 2017

HAL is a multi-disciplinary open access archive for the deposit and dissemination of scientific research documents, whether they are published or not. The documents may come from teaching and research institutions in France or abroad, or from public or private research centers.
L'archive ouverte pluridisciplinaire HAL, est destinée au dépôt et à la diffusion de documents scientifiques de niveau recherche, publiés ou non, émanant des établissements d'enseignement et de recherche français ou étrangers, des laboratoires publics ou privés. 


\title{
Optimization and lifecycle engineering for design and manufacture of recycled aluminium parts
}

\author{
Julien Le Duigou ${ }^{\mathrm{a}}$, Sverre Gulbrandsen-Dahl ${ }^{\mathrm{b}}$, Flore Vallet ${ }^{\mathrm{a}}$, Rikard Söderberg $(2)^{\mathrm{c}}$, \\ Benoît Eynard ${ }^{\mathrm{a}, *}$, Nicolas Perry $(2)^{\mathrm{d}}$ \\ ${ }^{a}$ Université de Technologie de Compiègne, UMR 7337 Roberval, CS 60319 - rue du Dr Schweitzer, 60203 Compiègne, France \\ b SINTEF Raufoss Manufacturing AS, Enggata 40, 2830 Raufoss, Norway

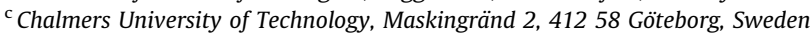 \\ ${ }^{\mathrm{d}}$ Arts et Métiers ParisTech, UMR 5295 I2M, Esplanade des Arts et Métiers, F-33400 Talence, France
}

\section{Keywords:}

Design

Optimization

Lifecycle

\begin{abstract}
A B S T R A C T
Aluminium alloys components are numerous in aeronautic and automobile structures. Despite having interesting mechanical properties for lightweight solutions, the extraction of virgin aluminium still has negative impacts on the environment. A solution is to use an increased rate of recycled aluminium in structural parts. This requires a global optimization of the part design and manufacture. The proposed work details the advanced optimization techniques used for product and process design integrating environmental concerns. The methodology is implemented and tested on an industrial case that results in a recycling rate of $75 \%$ in high-end structural component based on wrought aluminium alloys.
\end{abstract}

\section{Introduction}

Optimized lightweight manufacturing of parts is crucial for automotive and aeronautical industries in order to stay competitive, and reduce costs and fuel consumption. Hence, aluminium becomes an unquestionable material candidate regarding these challenges. Nevertheless, using only virgin aluminium is not satisfactory since its extraction requires high use of energy, and its manufacturing has high environmental impacts. For these reasons, the use of recycled aluminium alloys is recommended since their properties meet the expected technical and environmental requirements [1]. This requires complete reengineering of the classical lifecycle of aluminium-based products and several interdependent disciplines need all to be taken into account for a global product/process optimization [2]. Towards this end, the paper proposes a method for sustainability assessment integration into product lifecycle engineering and a platform for lifecycle simulation integrating environmental concerns. The platform may be used as a decision support system in early product design phase by simulating the lifecycle of a product (from material selection to production and recycling phases) and calculating its impact on the environment.

\subsection{Sustainable engineering, integrated lifecycle and design optimization}

Design, as defined in [3] is a complex and multifaceted phenomenon involving a tight collaboration between multi-domain

\footnotetext{
* Corresponding author.

E-mail address: benoit.eynard@utc.fr (B. Eynard).
}

product designers, a multitude of activities and procedures, tools and knowledge, as well as a variety of contexts.

Collaboration between multi-domain product designers implies that different points of view must be taken into account to achieve the best compromise in product development [4]. A point of view is the vision and knowledge of an expert involved in a design team [5]. An expert may be specialist of a particular lifecycle stage (e.g. manufacturing), a domain (e.g. mechanical engineer) or cross-domain (who brings expertise not linked to a life stage or a domain, but to a specific point of view on the whole lifecycle of a product, as for example the quality engineer or the environmental expert).

The environmental experts often have difficulties to share environmental information with other design experts [6,7]. This could be due to the nature of the results (e.g. environmental impacts) which are difficult to link with other design parameters (material specifications, geometric models, etc.). It can also be due to the absence of a standard exchange format that encompasses environmental parameters, like STEP (Standard for the Exchange of Product model data) that allows information exchange between various experts tools [8]. This results in the lack of interoperability between the systems used in design and those used by the environmental experts.

To go beyond these issues, Rio [9] proposed a model-driven architecture based interoperability method to improve exchange of information between eco-design and other design activities. Some software vendors worked on the integration of sustainability in traditional design tools like CAD systems (Solidworks from Dassault Systèmes) or material selection tools (CES selector from Granta Design). Russo and Rizzi [10] suggested another integrated eco-design method, including shape, material and production 
assessment integrating Life Cycle Assessment (LCA) with CAD and Finite Element Analysis. But those modules focus on a specific design stage and do not consider environmental impacts on the whole lifecycle. Other researchers, like Dufrene et al. [11] proposed an integrated eco-design methodology that improves both environmental impacts and technical characteristics.

One of the major difficulties the environmental experts have to cope with is the lack of information especially when they try to perform LCA $[12,13]$. LCA is time and resource consuming and requires a huge amount of heterogeneous data from all over the extended enterprise. Stark and Pförtner [14] proposed an ontological approach to assess sustainability based on information from IT systems and calculation rules. Some of this information could be extracted from the digital mock-up. This requires integration between CAD, Product Lifecycle Management and LCA, but to make a clear and useful analysis of environmental impacts, this information must be specialized and accurate [15].

\subsection{Objective}

A design methodology that integrates whole lifecycle environmental impact assessment into a product design optimization loop is not yet realized. In order to include the entire lifecycle environmental impact, the assessment of the optimized design should take into consideration the extraction, manufacturing, distribution, use and end of life. This leads to a methodology that integrates environmental concerns into a closed loop design optimization. The optimization includes material choice (based on recycled aluminium compositions), topology optimization for this particular material, optimization of processes and tolerances, and simplified environmental assessment. The objective is to propose new materials, processes and parts design that fulfil high level requirements and decrease total environmental impacts.

\section{Proposal: the SuPLight closed loop design methodology}

The methodology is developed in the European project SuPLight (Sustainable and efficient Production of Light weight solutions). SuPLight is a multidisciplinary research project, combining physics at the atomic scale level, metallurgy, continuum mechanics, structural mechanics, optimization algorithms, tolerance analysis, and manufacturing and lifecycle assessment. SuPLight proposes to reduce weight in structural parts and improve the holistic ecodesign of aluminium wrought alloys and to build novel sustainable industry models with a holistic lifecycle approach.

This methodology is based on an optimization loop on material, part topology, processes and parts tolerances and environmental assessment (Fig. 1). It is supported by an integrated optimization platform that supports automatic data exchange between the different tools.

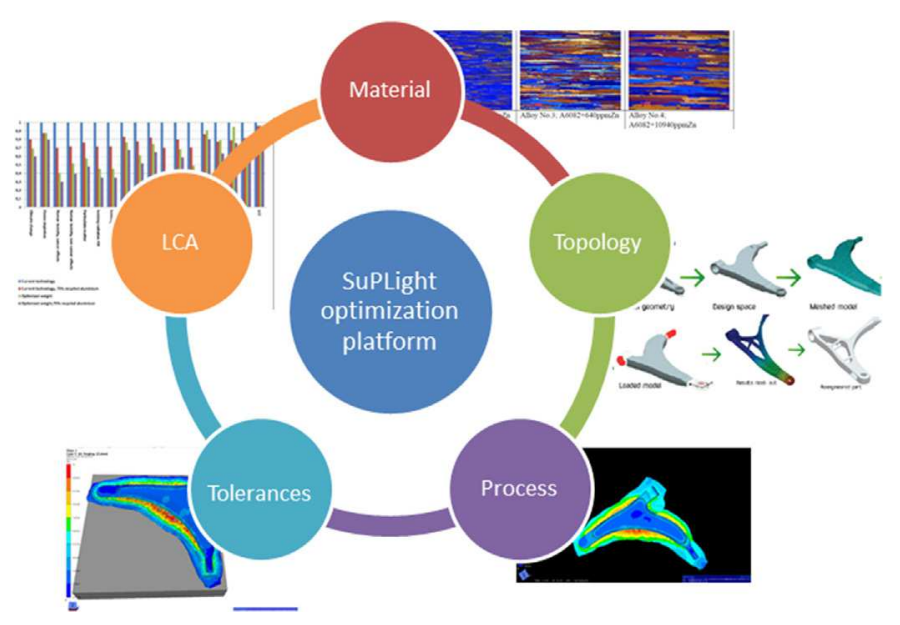

Fig. 1. SuPLight overall methodology.
The material phase determines the material and mechanical properties of the alloys which are later used by the design optimization and process phases to calculate the behaviour of the alloy parts.

The design optimization performs an analysis in order to find alternative topologies for the part that fulfil the stiffness, weight criteria, eigenvalues and centre of gravity requirements. The output of this phase includes the geometry definition used as an input to the process optimization phase.

The process optimization phase assesses the forging process for the part defined by the design optimization. The output of this phase includes the geometric definition for the tolerance phase input.

The tolerance optimization uses a meta-model for tolerance analysis and geometric variation simulation to provide rapid results based on a more extensive computation module.

The environmental assessment computes environmental impacts based on the characteristics of the product. The simplified lifecycle assessment of the part (in its context of usage) is based on the inputs from the other phases.

\subsection{Material}

Based on the chemical composition of the target alloy and its processing path the analysis returns the set of relevant material properties. The composition of the alloy can be specified by its unique ID based on the predefined set of alloys or by element composition. The processing path can be either (1) die cast and forging, (2) continuous casting and forging, or (3) continuous casting, extrusion and forging.

The material properties are calculated using two different scenarios: basic usage and advanced usage. In the case of basic usage, the material properties are evaluated by means of metamodels based on the experimental data. On the other hand the advanced operations allow the evaluation of mechanical properties of the alloy by metallurgical precipitation hardening model. In the initial stage the model is based on classical KampmannWagner model [16]. Due to the known limitations of this model with respect to thermodynamics, the additional model SFFK was implemented [17]. The latter model gives the possibility to overcome limitations of Kampmann-Wagner model approach by allowing modelling of multicomponent and even multiphase systems. The developed framework allows wide range of adaptations of the model and introductions of additional components. As a first validation, successful initial testing was performed using the thermodynamic data from literature and other sources.

\subsection{Topology optimization}

In structural optimization, the use of different sets of data representing a mathematical model describes the behaviour of a structure. Different control parameters are tuned by a set of design variables to find a situation in which the structure meets a given property. Shape optimization consists of optimizing the structure by changing the shape. Shape optimization has an interdisciplinary character, meaning it can be used on a wide range of problems. This kind of problems involves mathematical disciplines as partial differential equations, approximations of these and theory of nonlinear mathematical programming. This process is an automated and integrated task in the proposed framework.

\subsection{Process/manufacture engineering}

The use of specialized codes to predict material flow during forging has been developed together with of the rapid growing of computer-aided engineering, e.g. FORGE NxT. In contrast to structural design, the codes for handling forging are typical set up to manage large strains and deformations. Combining the predictive capabilities in such codes with an optimization engine gives an advantage for designing sustainable and optimal forging 
processes. The aim of the forging phase is to sort out the best design which will fill the dies without flow errors.

One approach to reach this goal is to use a pre-shape design and let the optimization engine scale the shape based on the centre of gravity. A second approach is to utilize the same principals described in the structural optimization on the pre-shape. In this work it was chosen to do the scaling approach on the forging optimization, given that the structural strategy has already been demonstrated on the product design.

This phase is dependent on receiving two central inputs. First it needs a geometry definition of the desired end product; second a description of the material to use. The end product is then subjected to a "forgeability" assessment which sorts out to smooth the part including draft angles and radiuses. The next step is to subtract the dies including the necessary flesh thickness. The dies are then individually prepared for the pre-forging set up.

In the pre-forging set up, the prepared geometries of the dies are converted to a representative numerical node mesh. To complete the set-up process, all process specific details are decided. Based on the material composition a forging billet temperature is set, together with the interaction coefficients and heat transfer number. Furthermore, the type of press and stroke kinematics is defined, together with the storing increment density. The project is then ready for the process optimization phase.

To eliminate designs that could represent an under filling, constrains are introduced in the optimization. Two sets of constrains are used. First the billet needs to be in contact with all surfaces that describe the end product. Lack of such contact will breach the constraint and the result is returned as not valid. Second, the scalar that represents an evaluation of flow error or self-contact within the domain of the desired end product needs to be zero. Results which deviate from zero are breaching the constraint and are thus not valid. The process optimization phase is set up to disregard the not valid design and uses a cost function to find the lowest weight of the initial pre-shape that still upholds the constraints.

\subsection{Tolerances definition}

All manufacturing processes are subject to variations, which may affect the way that the final product will meet its specifications. Variation sources can be in material properties or manufacturing conditions such as stamping pressure, thermal conduction, temperature, friction, etc. It is therefore of highest importance to consider this variation in the input parameters during design phases and try to predict how they will affect the output performance parameters. In assembled products, the geometric deformation of individual parts is very important for of manufacturing operations and for variation simulation of assemblies.

To predict variation in the final geometry due to variation in material and manufacturing parameters, variation simulation based on statistical calculations and expected distributions for input parameters is used. Since variation simulation will be conducted on computationally expensive finite elements models, meta models in combination with Monte Carlo simulation is used to predict the final geometric variation [18].

\subsection{Environmental assessment}

The final aim of this phase is to provide an evaluation of the designed part whole lifecycle environmental impact. This evaluation realized by an LCA tool is coupled with an eco-design approach. The developed approach consists at first of linking the key environmental indicators evaluated by the LCA tool to the different parameters in the whole product lifecycle, such as material, type of manufacturing process, etc. Then it links these parameters to possible improvements and solutions to reduce environmental impact [19]. The final output of the environmental assessment is the impact of the actual design and improvement recommendations. The product designers choose to validate or not some of these recommendations and restart the entire optimization loop until the environmental impact is satisfactory.

\section{Case study}

\subsection{Test case definition}

The considered part for the case study presented in this section, is a front lower control arm, which is a part of the suspension system of a car (see Fig. 2). The chosen control arm is manufactured from AA6082 which is a high strength wrought aluminium alloy. The baseline process for the manufacturing of the control arm is: (1) manufacturing of AA6082 ingots from virgin aluminium and treated production scrap; (2) extrusion of ingots to produce the AA6082 rods; (3) cutting rods into pieces and annealing to soften the billet and make it easier to forge; (4) rods forging; (5) ageing rods; (6) machining and assembly of the control arm.

The production (or pre-consumer) scrap is treated to remove the fluids and dirt and is then reused in the manufacturing of the AA6082 ingot. The aluminium recycling process (post customer scrap) is described in [20].

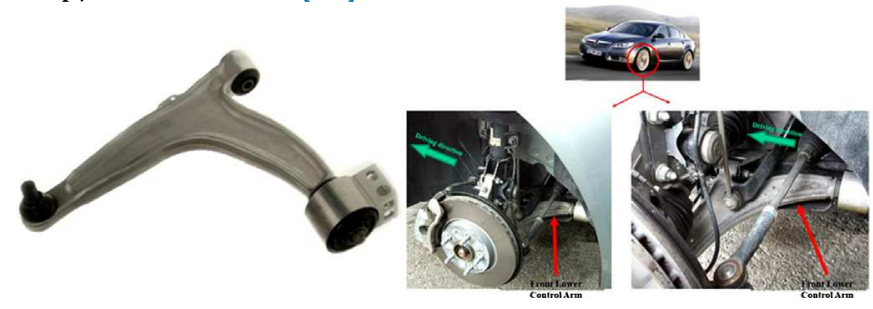

Fig. 2. The front lower control arm.

Three scenarios were proposed, with the purpose of specifying the optimal aluminium alloy properties to be used for the control arm to achieve the best global performance (in terms of resistance, rate of recycled aluminium or environmental impacts).

Details of the simplified LCA model for the present part design are available in [19]. The 3 scenarios which are compared to the present design and technology are: (1) new alloy based on $75 \%$ post-consumer scrap; (2) optimized product and process with respect to weight; (3) new alloy based on $75 \%$ post-consumer scrap and optimized product and process with respect to weight. They use the primary aluminium and recycled aluminium compositions presented in Table 1.

Table 1

Aluminium (AL) alloys compositions.

\begin{tabular}{lllllll}
\hline & SI & Mg & Fe & Cu & Mn & Zn \\
\hline Primary AL & 0.98 & 0.69 & 0.15 & 0 & 0.43 & 0.03 \\
Recycled AL & 0.92 & 0.75 & 0.16 & 0.01 & 0.4 & 1.1 \\
\hline
\end{tabular}

\subsection{Platform implementation}

The different phases are implemented by a set of plugins: material plugin, topology optimization plugin, process plugin, tolerances plugin and environmental plugin. The plugins have their own interfaces and some of them may also be used as independent software. In this case, they have two functioning modes (independent and integrated mode). A common format was specified to set a standardized format for enabling information exchange and management based on a dictionary. All "Simple Object Access Protocol" messages sent between the communicating modules follow the rules settled by the standardized format. In the integrated mode, they run as part of the closed-loop and they are provided with a common interface, accessible online within the SuPLight simulation platform (https://collab.suplight.eu/sim/). Web services were defined and implemented for each plugin, 
according to their legacy format. Servlets handle web service calls from the SuPLight platform and translates them into legacy format. The module for information management (ModeFrontier) handles the execution of the plugins in the optimization loop. At this level, the plugin sequence and the mapping between the input and output of each plugin are managed. In the front-end, the execution sequence may be set from the Graphical User Interface and the execution of the simulation sequence may be visualized step-bystep (results from each plugin) or at-once (final result).

\section{Results and discussion}

When the optimal parameterization strategy was chosen, automatic optimization in ModeFrontier generated weight savings of $6.26 \%$ which is a quite good result considering these products have been in mass production for years.

The reference mass necessary to forge the reference FLCA has been taken from the production input and is measured to be $2700 \mathrm{~g}$. After 40 runs within the optimization plugin the lowest initial pre-shape weight is estimated to be a reduction of mass compared to the reference mass of $16.4 \%$. A secondary effect with the new reduced mass is a lowering of forging loads from 1650 tonnes to 1600 tonnes. Table 2

The optimization results are summarized in Table 2 .

Optimization results from the test case.

\begin{tabular}{llll}
\hline & Recycling level & Shape optimization & Process optimization \\
\hline Result & $75 \%$ & $93.74 \%$ weight & $82.67 \%$ weight \\
\hline
\end{tabular}

The reduction of weight influences the whole life cycle of the product and reduces the total environmental impact. In case of FLCA, reduction of weight combined with using recycled aluminium and changing the production route result in a reduction of environmental impacts between 24 and 50\% at the highest (for water withdrawal - Scenario 2), see Fig. 3. The results from simplified LCA in the SuPLight framework are presented in Fig. 3 as fractions of environmental impacts of the present design and technology.

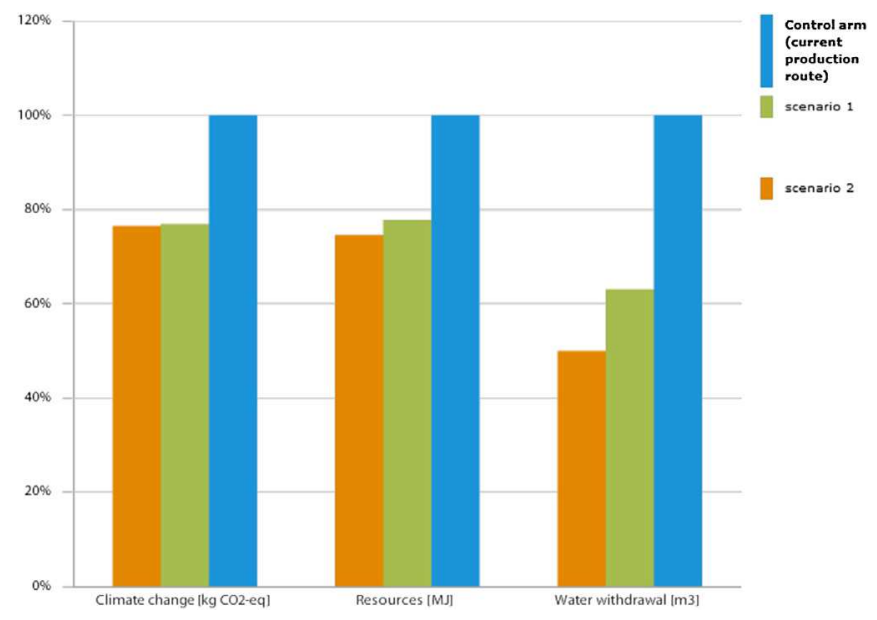

Fig. 3. Simplified LCA results from test case.

\section{Conclusion and future work}

This paper proposed a framework for an optimization loop of structural part design including environmental assessment through an aluminium part redesign integrating a high level of post-customer scrap. This framework is implemented on a numerical platform and test on an automotive part.
This work shows that an integrated approach from material to production and environmental assessment is necessary. The needed information is processed through the different phases and several optimization loops are necessary to find the best solution.

Other lifecycle phases should be integrated to propose a more complete analysis. The production phase is reduced to the forging step in the presented process. A more complex optimization of the production routes can offer new perspectives.

This also offers the perspective for the development of a specific reverse logistic business that selects and sorts end customer scrap depending on the aluminium component for specific applications. This new industrial model could allow the implementation of the proposed methodology with sufficient recycled aluminium quantity and an acceptable chemical composition.

\section{Acknowledgements}

The authors would like to acknowledge the European Commission for its financial support through the SuPLight FP7 project (grant agreement $n^{\circ} 263302$ ) and support from the research centre SFI Manufacturing supported by the Research Council of Norway.

\section{References}

[1] Duflou JR, Tekkaya AE, Haase M, Welo T, Vanmeensel K, Kellens K, Dewulf W, Paraskevas D (2015) Environmental Assessment of Solid State Recycling Routes for Aluminium Alloys: Can Solid State Processes Significantly Reduce the Environmental Impact of Aluminium Recycling? CIRP Annals - Manufacturing Technology 64(1):37-40.

[2] Perry N, Bernard A, Bosch-Mauchand M, Le Duigou J, Xu Y (2014) Proposal of an Architectural Solution for Economic and Environment Global Eco-cost Assessment: Models Combination Analysis. in Henriques E, Peças P, Silva A, (Eds.) Technology and Manufacturing Process Selection: The Product Life Cycle Perspective, 239-256.

[3] Blessing LT, Chakrabarti A (2009) DRM - A Design Research Methodology, Springer-Verlag, London.

[4] Sohlenius G (1992) Concurrent Engineering. CIRP Annals - Manufacturing Technology 41(2):645-655.

[5] Brissaud D, Tichkiewitch S (2001) Product Models for Life Cycle. CIRP Annals Manufacturing Technology 50(1):105-108.

[6] Lindhal M (2006) Engineering Designers' Experience of Design for Environment Methods and Tools-Requirement Definitions From an Interview Study. Journal of Cleaner Production 14(5):487-496.

[7] Kozemjakin da Silva M, Remy S, Reyes T (2015) On Providing Design Process Information to the Environmental Expert. Research in Engineering Design 26(4):327-336.

[8] Chandrasegaran SK, Ramani K, Sriram RD, Horváth I, Bernard A, Harik RF (2013) The Evolution, Challenges, and Future of Knowledge Representation in Product Design Systems. Computer-Aided Design 45(2):204-228.

[9] Rio M, Reyes T, Roucoules L (2014) FESTivE: An Information System Method to Improve Product Designers and Environmental Experts Information Exchanges. Journal of Cleaner Production 83:329-340.

[10] Russo D, Rizzi C (2014) Structural Optimization Strategies to Design Green Products. Computers in Industry 65(3):470-479.

[11] Dufrene M, Zwolinski P, Brissaud D (2013) An Engineering Platform to Support a Practical Integrated Eco-Design Methodology. CIRP Annals - Manufacturing Technology 62(1):131-134.

[12] Curran MA (2006) Life Cycle Assessment: Principles and Practice. EPA/600/R-06/ 060

[13] ISO14040 (2006) Environmental Management - Life Cycle Assessment - Principles and Framework, International Standard Organisation, Geneva.

[14] Stark R, Pförtner A (2015) Integrating Ontology into PLM-Tools to Improve Sustainable Product Development. CIRP Annals - Manufacturing Technology 64(1):157-160.

[15] Pavković N, Štorga M, Bojčetić N, Marjanović D (2013) Facilitating Design Communication Through Engineering Information Traceability. Artificial Intelligence for Engineering Design Analysis and Manufacturing 27(2):105-119.

[16] Myhr OR, Grong Ø., Pedersen KO (2010) A Combined Precipitation, Yield Strength, and Work Hardening Model for Al-Mg-Si Alloys. Metallurgical and Materials Transactions A 41(9):2276-2289.

[17] Svoboda J, Fischer FD, Fratzl P, Kozeschnik E (2004) Modelling of Kinetics in Multi-Component Multi-Phase Systems With Spherical Precipitates: I: Theory. Materials Science and Engineering A 385(1-2):166-174.

[18] Hoffenson S, Dagman A, Söderberg R (2015) Tolerance Optimisation Considering Economic and Environmental Sustainability. Journal of Engineering Design 25(10-12):367-390.

[19] Andriankaja H, Vallet F, Le Duigou J, Eynard B (2015) A Method to Ecodesign Structural Parts in the Transport Sector Based on Product Life Cycle Management. Journal of Cleaner Production 94:165-176.

[20] Global Aluminium Recycling (2009) A Cornerstone of Sustainable Development, International Aluminium Institute. 